\section{Changes in the Indo-Gangetic Alluvial Plain.}

I $N$ a paper on this subject to Section $E$ (Geography) of the British Association at Liverpool, Mr. W. H. Arden-Wood threw interesting light on the past geography of the country as read from tradition, history, and the deserted sites of towns. The enormous changes in the river systems of the IndoGangetic alluvial plain make it certain that it is quite fallacious to assume that the topography of, say, the Punjab was the same 2000 years ago as it is to-day. No doubt many of the ancient cities of India owed their abandonment or decline to changes in the political importance of the states to which they belonged or to changes which made them no longer suitable as a seat of government; others to the result of warfare. But most of the cities stood on rivers which in some cases washed them away or in other cases deserted them.

A deserted river reach becomes full of stagnant water choked with vegetation. This provides an excellent breeding ground for the malarial mosquito. Thus a town bereft of its river may become so unhealthy that it is virtually abandoned. Gaur, once the capital of Bengal, was deserted by the Ganges three centuries ago and abandoned after the ravages of a frightful pestilence. In times of flood extensive changes in the river courses are specially apt to occur. Examples were cited in the case of the Damodar and the Hooghli.

Mr. Arden-Wood went on to show how interference with the flow of rivers caused by the construction of canals has had far-reaching effects in certain cases where the gradient of the river is low. Thus the confluence of the Indus and Chenab is now sixty miles below the old confluence, owing to the construction of an irrigation canal between the two. Both from geographical evidence and from the many important towns on its banks, it would appear that the Hooghli was once the main stream of the Ganges. But the Hooghli has now reached a stage where it is ceasing to hold its own as a live river. For the greater part of the year it receives little or no water from the Ganges; its bed is probably at a higher level than that of the main stream and it is steadily deteriorating as a navigable river. Changes in the Bidyadhari, a tidal deltaic river east of Calcutta into which the city drainage flows, are rapid and threaten the health of the city. Remedial measures are being taken, but may not be sufficient to overcome the tendency for the Bidyadhari, as a flowing river, to die.

\section{Alternation of Generations in the Ectocarpaceæ.}

A PAPER by Miss Margery Knight, published in the A Transactions of the Royal Society of Edinburgh, vol. 53, part ii., No. I7, upon the life-history and cytology of Pylaiella litovalis Kjellm., provides data of very considerable interest to the student of the Algæ. The paper is unusually full of the marine student's equivalent for " field" observations, and Miss Knight must have given some time and trouble to her studies of these small plants in their natural habitat and also to their cultivation under experimental conditions.

As a result, she reports a most interesting interdependence of the spore forms of Pylaiella and the Fucoid supports upon which the filamentous alga usually develops. In the spring, young Pylaiella plants are mainly met with upon Ascophyllum nodo- sum; in the early summer the new fronds of Fucus vesiculosus are covered with young Pylaiella plants, the latter soon outstripping in size the plants growing upon Ascophyllum; towards the end of the summer another series of plants are found upon Fucus serratus. Miss Knight reports that 90 per cent. of the Pylaiella plants on Ascophyllum have plurilocular sporangia only, whilst the plants upon the Fucus hosts consistently bear unilocular sporangia, with the exception of some 2 per cent. of the plants on $F$. serratus and I5 per cent. on $F$. vesiculosus.

The cytological investigation has established a reduction of the chromosome number in the formation of the unilocular sporangia. From these structures a haploid generation must arise, but the prevalence of diploid plants with plurilocular sporangia necessitates the acceptance of nuclear fusion as an integral part of the life-cycle of at least some of the plants. Miss Knight has frequently observed gametic fusion, particularly under certain cited conditions, but she has also to report a strongly developed tendency to parthenogenetic spore development. The basal alternation would thus seem to be, in this member of the Ectocarpaceæ, a transition from a diploid plant through unilocular sporangia with haploid spores, to the haploid individual with gametes in plurilocular gametangia the fusion of which re-establishes the diploid condition. But the rapid completion of the life-cycle may be delayed, either by a long succession of diploid individuals with plurilocular sporangia in which nuclear reduction fails to take place or by a long succession of haploid individuals reproducing parthenogenetically.

Algal systematists will be interested by the polymorphism of the species of Pylaiella revealed by Miss Knight's study of the same individual plants at different seasons of the year, and under different experimental conditions. The dependence of the form of Algal reproductive cell upon external conditions is indeed strikingly emphasised by this work, especially in the remarkable instance cited in which, by removing a screen of Fucus fronds above it, a patch of Plumaria elegans lying on a sunken breakwater was caused to produce tetrosporangia within eight days, this patch lying in a carpet of Plumaria still shaded by the Fucus fronds which uniformly produced cystocarps.

\section{On Continuous Radiation from the Sun.}

R. W. ANDERSON, in a paper in the Astronomische Nachrichten. No. 5239, directs attention to the fact that Wilsing has recently raised serious objections to the theory that the continuous spectrum of the photosphere is due to light from the gaseous interior of the sun. Dr. Anderson explains the difficulty of assuming the existence of solid or liquid particles in the photosphere; and shows that even particles of carbon could only exist, at an assumed photosphere temperature of $54.00^{\circ} \mathrm{A}$., if the total pressure were several hundreds or even thousands of atmospheres, which seems quite impossible; the actual temperature according to Hirayama is $7040^{\circ} \mathrm{A}$. A " mist" of minute particles, could such be produced, would be of a most ephemeral nature, since it is possible to deduce from Stefan's observations on the velocity of evaporation that the time of evaporation is proportional to the square of the radius, and so will be very small indeed for spheres of small radius.

It is suggested that a solution of the difficulty may perhaps be obtained as follows: the Zeeman effect in the sun-spots proves that the photosphere is

$$
\text { No. } 2830 \text {, voL. I I } 3]
$$

